\title{
Analisis Harga, Kualitas Produk, Citra Merek Dan Keputusan Pembelian Produk Smartphone Xiaomi
}

\author{
Listiana $^{1^{*}}$, Nur Aida ${ }^{1}$ \\ ${ }^{1}$ Program Studi Manajemen STIE Gempol \\ Jl. Raya Pasar No 9 Gempol Pasuruan 67155 Jawa Timur
}

`Email: listiyanalis@gmail.com

Naskah diterima 15 Desember 2020, Revisi 15 Maret 2021, Terbit 29 April 2021

\begin{abstract}
DOI: doi.org/10.21107/pamator.v14i1.10121

This study aims to determine the effect of price variables, product quality and brand image on purchasing decisions for Xiaomi smartphones and to find out the role of brand image as a mediating variable between price and product quality on purchasing decisions for Xiaomi smartphones. The study population was users or had used Xiaomi in the Pasuruan area with a total sample size of 97 with a purposive sampling method and analysis was carried out with the SmartPLS 3 application. All research indicators have a loading factor above 0.7 and all research indicators have AVE $>0.5$. The reliability of the data was tested because it had a Cronbach Alpha value and a composite reliability $>0.7$. The predicted relevance value is high with Q2>0.00 so that the research is feasible. The results of the study concluded that the price had a positive but insignificant effect on purchasing decisions. Product quality and brand image have a positive and significant effect on purchasing decisions, product quality has a positive and significant effect on brand image, prices have a positive but insignificant effect on brand image. For mediation analysis, it is concluded that brand image is a potential moderation between price and purchase decision. branding is a quasi-moderation for product quality to influence purchasing decisions. The NFI value is 0.807 , which means that the model is fit because it is close to unity.
\end{abstract}

Key words: price, procuct quality, brand image, purchase decision

\section{PENDAHULUAN}

Perkembangan dunia komunikai saat ini berkembang pesat seiring dengan semakin mudahnya orang behubungan dengan orang lain dan perkembangan ini sangat dipengaruhi oleh keberadaan handphone yang sudah menjadi kebutuhan utama masyarakat di semua kalangan, disegala usia, disegala strata kehidupan ekonomi dan social. Tentu ini merupakan pasar yang sangat menarik bagi produsen handphone sehingga muncul banyak produsen baru dengan berbagai merek berbagai fitur yang lebih baik sehingga fungsi handphone saat ini bukan sekedar komunikasi tradisional seperti telpon atau sms semata tapi handphone sudah berubah menjadi smartphone karena berbagai aplikasi, fitur yang ditawarkannya. Bahkan smartphone juga terkadang dijadikan "gaya hidup" bagi segelintir orang (Vi, 2017). Berikut data market share 5 perusahaan smartphone 2020 (Gambar 1). Berdasarkan peta market share diatas Nampak Xiaomi berada ada peringkat empat pada periode kuartal pertama 2020 dibawah Vivo, Oppo,
Samsung, ada kenaikan market share dibanding kuartal sebelumnya.

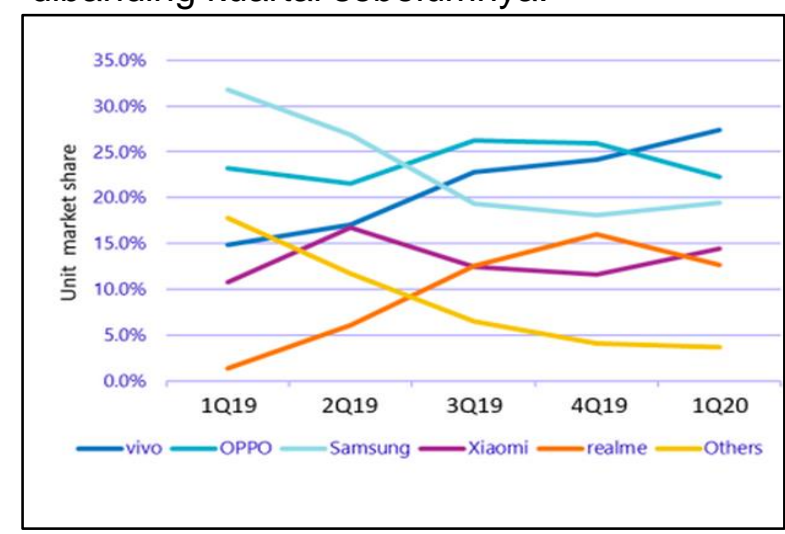

Gambar 1. Indonesia Top 5 Smartphone Companies 1Q20 Unit Market Share

Setiap produk yang ditawarkan harus dipastikan mempunyai kualitas produk yang baik agar bisa unggul dalam persaingan karena keunggulan kualitas merupakan salah satu daya saing untuk bisa merebut minat konsumen dalam melakukan pembelian (Kusumawardhani, 2018) dan merupakan pertimbangan berikut dari konsumen selain 
harga karena kualitas produk berkaitan dengan kebutuhan fisik maupun psikologis konsumen secara maksimal (Zhang et al., 2015). Selain kualitas produk yang mumpuni maka harga juga menjadi pertimbangan penting karena harga merupakan salah satu nilai untuk memposisikan produk lebih unggul dibanding produk pesaing dan penetapan harga harus cermat karena kesalahan dalam penetapan harga bisa memposisikan perusahaan dalam kerugian atau bahkan kehilangan pasar.

Penetapan harga yang tepat dengan kualitas produk yang mumpuni diimbangi dengan citra merek yang baik tentu akan mendorong tingkat penjualan. Citra merek sangat menentukan sikap dan tindakan konsumen dan merupakan unsur penting yang mendorong konsumen melakukan pembelian. Akan semakin banyak konsumen yang membeli sebuah produk apabila citra merek dikenal sangat baik karena dipercaya citra merek yang baik akan bisa dipercaya dalam memberikan keamanan sebuah produk (Pradana et al., 2018). Citra merek mampu mempengaruhi keuntungan jangka Panjang, meningkatkan harga saham, competitive advantage dan mendorong terciptanya minat konsumen melakukan pembelian serta suksesnya kegiatan pemasaran (Yoo \& Donthu, 2001). Faktor kepercayaan pada merek sangat besar pengaruhnya bagi konsumen untuk melakukan pembelian.

Dengan semakin banyak pesaing semakin banyak pula pilihan bagi konsumen untuk bisa mendapatkan barang yang sesuai harapan (Igir et al., 2018) untuk itu setiap perusahaan harus berlomba lomba untuk bisa merebut pasar sebesar mungkin melalui berbagai strategi marketing. Xiaomi sebagai perusahaan tentu ingin memperbaiki posisi dalam peta persaingan dengan produsen lain, mengingat posisi market sharenya masih di posisi empat, maka strategi penetapan harga yang tepat, kualitas produk yang mumpuni serta menanamkan citra yang baik dimata konsumen menjadi pertimbangan yang sangat penting agar bisa mendorong penjualan yang lebih tinggi lagi.

\section{METODOLOGI}

Jenis penelitian ini penelitian kuantitatif asosiatif yaitu tentang hubungan satu variable dengan variable lainnya serta kuantitatif mediasi yaitu tentang kemampuan memediasi sebuah variable terhadap variable lainnya. Sumber data penelitian berupa data primer yaitu data didapat langsung dari responden berupa penyebaran questioner dimana skala ukurannya menggunakan skala likert dengan range 1 (sangat tidak setuju) sampai dengan 5 (sangat setuju).

Populasi penelitian adalah pengguna smartphone Xiaomi di daerah Pasuruan dengan jumlah sampel berdasarkan teori (Widiyanto, 2008) yaitu dengan menggunakan rumus $n=Z_{2} / 4$ (Moe) 2, dimana: $n=$ jumlah sampel $Z=Z$ score pada tingkat signifikansi tertentu (95\%) Moe = Margin of Error. Margin of error yang dipakai sebesar $10 \%$, didapat sampel minimal sebesar: $n=1,962 / 4(0,10) 2 n=96,04(97)$ dengan demikian jumlah sampel penelitian adalah 97. Metode pengambilan sampel yang dilakukan adalah purposive sampling yaitu sampel diambil dari responden pemilik atau pernah mempunyai smartphone Xiaomi.

Variable penelitian terdiri dari 2 jenis variable penelitian yaitu variable eksogen dan variable endogen dimana variable laten eksogen adalah Harga $\left(X_{1}\right)$ dan kualitas Produk $\left(X_{2}\right)$ sementara variable laten endogen adalah Citra Merek $\left(\mathrm{Y}_{1}\right)$ dan Keputusan Pembelian $\left(\mathrm{Y}_{2}\right)$. Variable Citra merk $\left(\mathrm{Y}_{1}\right)$ merupakan variable mediasi antar harga $\left(X_{1}\right)$, kualitas produk $\left(X_{2}\right)$ terhadap keputusan pembelian. Variable mediasi merupakan adalah variable penyela yang terletak antara variabel eksogen dan endogen sehingga variable eksogen tidak langsung mempengaruhi berubahnya variable endogen.

Alat uji yang digunakan adalah metode Structural Equation Modeling yang berbasis varian yaitu Partial Least Square (PLS) suatu teknik prediktif yang bisa menangani banyak variabel independen, bahkan sekalipun terjadi multikolinieritas diantara variabelvariabel tersebut (Ramzan dan Khan, 2010) disamping itu PLS merupakan metode analisis yang powerfull sebab tidak didasarkan pada banyak asumsi atau syarat, seperti uji normalitas dan multikolinearitas 
Dengan PLS akan didapatkan keterkaitan antara variable laten atau variable yang tidak dapat diukur langsung dan variable pengamatan (indikator). Metode PLS terdiri dari model struktural dan model pengukuran. Model structural atau inner model merupakan model tentang hubungan antar variable laten sementara model pengukuran atau outer model merupakan model tentang hubungan antara variable dengan masing masing indikatornya. Tahapan dalam evaluasi PLS terdiri dari evaluasi pada model pengukuran kemudan evaluasi pada model structural ( Santoso, 2018).

\section{Evaluasi Untuk Model Pengukuran} (Measurement Model) atau Outer Model

1. Pengukuran validitas dilakukan dengan melihat pada nilai loading factor dimana nilai loading factor atau outer loading minimal 0.7 sehingga untuk indikator yang mempunyai loading factor dibawah 0.7 maka indikator tersebut harus dihapus.

2. Average Variance Extracted (AVE) merupakan ukuran dalam pengujian validitas konvergen. Batasan nilai AVE adalah > 0.5. Jika nilai AVE didapatkan lebih besar dari 0,5 maka indikatorindikator di dalam model yang dikembangkan terbukti benar-benar mengukur konstrak laten yang ditargetkan dan tidak mengukur konstrak laten yang lainnya.

3. Diskriminant validity diuji dengan melihat nilai pada cross lading dimana diskriminan validity ini dimaksudkan melihat nilai korelasi antara indikator dengan variable latennya > nilai korelasi indikator dengan variable lainnya.

4. Pengukuran reliability. Reliability merupakan pengukuran untuk mengetahui kehandalan dari suatu item pernyataan dimana suatu item pernyataan dikatakan reliabel apabila mempunyai Alpha Cronbach $>0.7$ dan Composite reliability $>0.7$.

\section{Evaluasi Untuk Model Struktural atau Inner Model}

1. $R^{2}$ dimana nilai $R$ ini menunjukkan besar pengaruh yang diberikan oleh variable endogen terhadap variable eksogen.
2. Path Koefisien menunjukkan arah hubungan variable eksogen terhadap variable endogen dimana nilai ini berada pada range -1 sampai dengan +1 . Tanda negative menunjukkan hubungan antar variable endogen dengan variable eksogen berkebalikan arah atau kalau variable eksogen naik maka variable endgen akan turun dan sebaliknya sementara nilai path koefisien bertanda positif menunjukkan hubungan antar variable endogen dan eksgen mempunyai arah yang sama artinya kalau variable eksogen naik maka variable endogen naik juga dan sebaliknya.

3. Nilai stone Geisser $\left(\mathrm{Q}^{2}\right)$ menunjukkan ukuran kebaikan sebuah model yang diobservasi. Dikatakan observasi sebuah model baik kalau mempunyai nilai $Q^{2}$ sebesar $>0.00$.

4. Model Fit dengan notasi normed fit index (NFI) merupakan ukuran ketepatan sebuah model semakin besar nilai NFI maka semakin tepat atau cocok model

\section{Uji Hipotesa}

Uji hipotesa yang dilakukan disini, dengan proses bootstrapping, dengan cut off point adalah nilai nilai $\mathrm{T}$ statistik $>1.96$ atau $\mathrm{P}$ value $<$ 0.05 . Apabila nilai $T$ statistik $>1.96$ atau nilai $P$ value $<0.05$ dikatakan pengaruh suatu variable terhadap variable lain adalah signifikan dan sebaliknya.

\section{HASIL PEMBAHASAN}

Analisa Partial Least Square (PLS) harga $\left(\mathrm{X}_{1}\right)$, kualitas produk $\left(\mathrm{X}_{2}\right)$, citra merek $\left(\mathrm{Y}_{1}\right)$ dan keputusan pembelian $\left(\mathrm{Y}_{2}\right)$. Dalam measurement model atau dikenal outer model menjelaskan hubungan antara indikator (manifest) dari masing-masing variable laten terhadap variabelnya. Factor loading diharuskan memiliki nilai minimal 0.7 untuk bisa dikatakan valid. Dari dari olah data pakai PLS didapatkan nilai loading dari indikator Y1.4 dan Y2.3 serta Y2.2 dibawah 0.7 sehingga ketiga indikator (manifest) tersebut dikeluarkan dari indikator penelitian. Setelah ketiga indikator dikeluarkan dari penelitian dan didapatkan output PLS dengan nilai loading semua indikator $>0.7$ sehingga dinyatakan valid dan dikatakan semua indikator sudah mampu mengukur variable. 


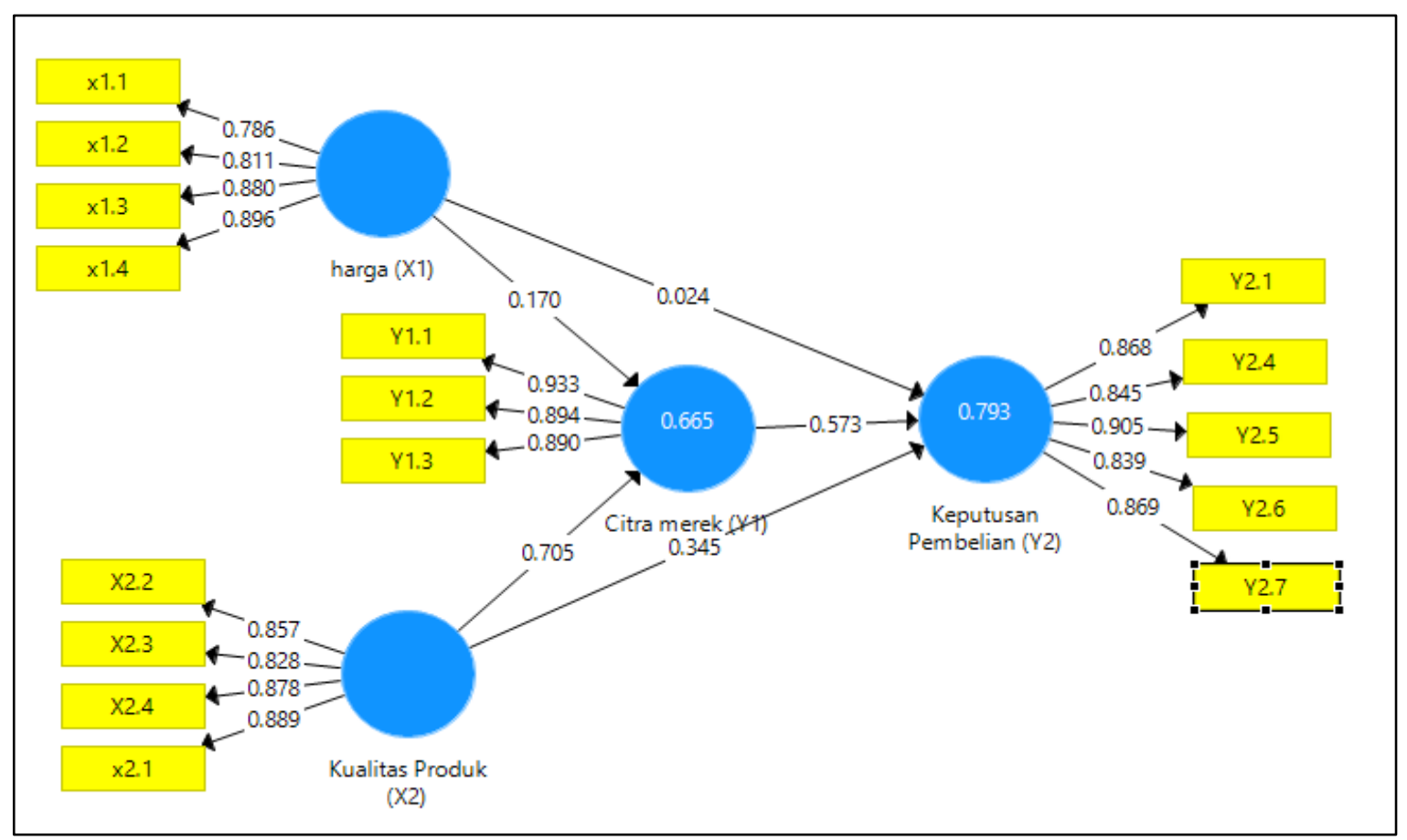

Gambar 2. Outer Model dan Inner Model

\section{Average Variance Extracted (AVE)}

Dalam konvergen validity didapatkan nilai AVE untuk menguji validitas konvergen dengan cut off point nilai AVE $>0,05$. Nilai AVE dari semua variable konstrak $>0,5$ sehingga indikator-indikator di dalam model yang dikembangkan terbukti mengukur konstrak laten yang ditargetkan dan tidak mengukur konstrak laten yang lain.

Tabel 1. Keluaran AVE

\begin{tabular}{ll}
\hline Konstruk & AVE \\
\hline Citra Merk & 0,821 \\
Keputusan Pembelian & 0,749 \\
Kualitas Produk & 0,745 \\
Harga & 0,713 \\
\hline
\end{tabular}

\section{Composit Reliability}

Setelah indikator dikatakan valid dan mampu dipakai mengukur variable maka dilakukan uji unidimensionalitas dengan melihat pada nilai Alpha Cronbach dan composit reliability dengan cut off poin kedua nilai uji tersebut diatas 0.7. Semua nilai Alpha Cronbach 0.7 dan composit reliability lebih besar dari 0.7 sehingga semua item pernyataan dikatakan reliabel.
Table 2. Composit Reliability

\begin{tabular}{llll}
\hline & $\begin{array}{c}\text { Cronbach`s } \\
\text { Alpha }\end{array}$ & $\begin{array}{c}\text { Composite } \\
\text { Reliability }\end{array}$ & $\begin{array}{c}\text { Average } \\
\text { Variance } \\
\text { Extracted } \\
\text { (AVE) }\end{array}$ \\
\hline $\begin{array}{l}\text { Citra Merk } \\
\text { Keputusan } \\
\begin{array}{l}\text { Pembelian } \\
\text { Kualitas }\end{array}\end{array}$ & 0.890 & 0.932 & 0.821 \\
$\begin{array}{l}\text { Produk } \\
\text { Harga }\end{array}$ & 0.886 & 0.937 & 0.749 \\
\hline
\end{tabular}

\section{Pengujian Struktur Model (Inner Model)}

Berdasar R square (Tabel 3) didapat nilai $\mathrm{R}$ square Citra Merek sebesar 0.655 artinya kemampuan menjelaskan variable laten Harga dan Kualitas Produk terhadap Citra merek sebesar $65.5 \%$, selebihnya yatu sebesar $34.5 \%$ variabel citra merek dijelaskan oleh variable lain diluar penelitian. $\mathrm{R}$ square untuk keputusan pembelian sebesar 0.793 sehingga dapat disimpulkan bahwa variable laten keputusan pembelian mampu dijelaskan oleh variable harga, kualitas produk dan Citra Merek sebesar $79.3 \%$ dan sisanya sebesar $20.7 \%$ keputusan pembelian dijelaskan oleh variable laten lainnya yang tidak dimasukkan dalam variable penelitian. Variable eksogen yang mempengaruhi citra merek maupun keputusan pembelian terhadap smartphone 
Xiaomi masih banyak bukan hanya kualitas produk maupun harga seperti fitur, citra perusahaan, citra produk, promosi dan sebagainya.

Tabel 3. R-Square

\begin{tabular}{lll}
\hline Variabel Laten & $R$ Square & $\begin{array}{l}R \text { Square } \\
\text { Adjusted }\end{array}$ \\
\hline Citra Merek & 0.655 & 0.657 \\
Keputusan & 0.793 & 0.786 \\
Pembelian & & \\
\hline
\end{tabular}

\section{Path Coefficients}

Path coeffisien dimaksudkan untuk melihat arah hubungan antara variable laten eksogen terhadap variable laten endogen dimana arah hubungan bisa positif dan bisa negative dengan range nilai antara -1 sampai dengan +1 . Kalau arah hubungannya negative artinya kalau variable laten eksogen naik maka variable laten endogen turun dan sebaliknya (mempunyai arah yang berkebalikan) sementara kalau arah hubungan positif artinya kalau variable laten eksogen naik maka variable laten endogen juga naik dan sebaliknya (searah).

Tabel 4. Path Koefisien

\begin{tabular}{lll}
\hline & Citra Merek & $\begin{array}{l}\text { Keputusan } \\
\text { Pembelian }\end{array}$ \\
\hline $\begin{array}{l}\text { Citra Merk } \\
\text { Keputusan }\end{array}$ & & 0.573 \\
$\begin{array}{l}\text { Pembelian } \\
\text { Kualitas Produk }\end{array}$ & 0.705 & 0.345 \\
Harga & 0.170 & 0.024 \\
\hline
\end{tabular}

Berdasarkan ouput pada Tabel 4 diatas didapatkan arah hubungan dari semua variable eksogen terhadap variable endogen adalah searah dan positif artinya kalau variable harga dan kualitas produk naik maka variable citra merek dan keputusan pembelian juga naik dan sebaliknya, terakhir kalau variable citra merek naik maka variable keputusan pembelian juga naik dan sebaliknya.

\section{Uji Hipotesa}

Hubungan Langsung (Direct Effect)

Analisa ini dilakukan untuk menguji signifikansi dari hubungan antara variable eksogen terhadap variable endogen dimana dasar pengujian pengaruh antar variable signifikan adalah dengan ketentuan nilai $\mathrm{T}$ stat $>1.96$ dan $\mathrm{P}-$ Value $<0.05$.
Tabel 5. Uji Hipotesa Hubungan Langsung

\begin{tabular}{lcccl}
\hline & $\begin{array}{c}\text { Original } \\
\text { Sample }\end{array}$ & T-Stat & $\begin{array}{c}P \\
\text { Value }\end{array}$ & Keterangan \\
\hline $\begin{array}{l}\text { Citra } \\
\text { Merek -> } \\
\text { Keputusan }\end{array}$ & 0.573 & 5.579 & 0.000 & Signifikan \\
$\begin{array}{l}\text { Pembelian } \\
\text { Kualitas }\end{array}$ & & & & \\
$\begin{array}{l}\text { Produk -> } \\
\text { Citra }\end{array}$ & 0.705 & 9.985 & 0.000 & Signifikan \\
$\begin{array}{l}\text { Merek } \\
\text { Kualitas }\end{array}$ & & & & \\
$\begin{array}{l}\text { Produk }-> \\
\text { Keputusan }\end{array}$ & 0.345 & 3.328 & 0.001 & Signifikan \\
$\begin{array}{l}\text { Pembelian } \\
\text { Harga -> } \\
\text { Citra }\end{array}$ & 0.170 & 1.960 & 0.051 & $\begin{array}{l}\text { Tidak } \\
\text { Merek }\end{array}$ \\
$\begin{array}{l}\text { Harga -> } \\
\text { Keputusan } \\
\text { Pembelian }\end{array}$ & 0.024 & 0.341 & 0.733 & $\begin{array}{l}\text { Tidak } \\
\text { Signifikan }\end{array}$ \\
\hline
\end{tabular}

Hubungan Tidak langsung (Specific Indirect Effects)

Pengaruh tidak langsung variable mediasi citra merk dari variable eksogen harga terhadap keputusan pembelian serta pengaruh mediasi variable eksogen kualitas produk terhadap keputusan pembelian.

Tabel 6. Uji Hipotesa Hubungan Tidak Langsung

\begin{tabular}{lcccl}
\hline & $\begin{array}{c}\text { Original } \\
\text { Sample }\end{array}$ & T-Stat & $\begin{array}{c}P \\
\text { Value }\end{array}$ & Keterangan \\
\hline $\begin{array}{l}\text { Kualitas } \\
\text { Produk -> } \\
\text { Citra }\end{array}$ & & & & \\
$\begin{array}{l}\text { Merek-> } \\
\text { Keput }\end{array}$ & 0.404 & 4.480 & 0.000 & Signifikan \\
$\begin{array}{l}\text { Pembelian } \\
\text { Harga -> }\end{array}$ & & & & \\
$\begin{array}{l}\text { Citra } \\
\text { Merek -> } \\
\text { Keputusan } \\
\text { Pembelian }\end{array}$ & 0.097 & 1.894 & 0.059 & $\begin{array}{l}\text { Tidak } \\
\text { Signifikan }\end{array}$ \\
\hline
\end{tabular}

Dari uji hipotesa pengaruh langsung dan tidak langsung diatas didapatkan hasil dimana variable citra merek merupakan Moderasi Potensial (Homologiser Moderator) antara harga terhadap keputusan pembelian sehingga citra merek berpotensi menjadi variabel moderasi. Sementara variabel citra merek merupakan moderasi semu (quasi moderasi) antara kualitas produk terhadap keputusan pembelian sehingga citra merek bisa berposisi sebagaivariabel eksogen. 
Tabel 7. Predicted Relevance Blind Folding

\begin{tabular}{llll}
\hline & SSO & SSE & $\begin{array}{l}\mathrm{Q}^{2} \\
(=S S E / S S O)\end{array}$ \\
\hline $\begin{array}{l}\text { Citra Merek } \\
(\mathrm{Y} 1)\end{array}$ & 291.000 & 385.762 & 0.533 \\
$\begin{array}{l}\text { Keputusan } \\
\text { Pembelian }\end{array}$ & 485.000 & 202.740 & 0.582 \\
$\begin{array}{l}\text { (Y2) } \\
\text { Kualitas }\end{array}$ & 388.000 & 388.000 & \\
$\begin{array}{l}\text { Produk (X2) } \\
\text { Harga (X1) }\end{array}$ & 388.000 & 388.000 & \\
\hline
\end{tabular}

Dari output PLS diatas didapatkan nilai stone Geisser $\left(\mathrm{Q}^{2}\right)$ dari citra merek adalah 0.533 dan keputusan pembelian sebesar 0.582 . Hal ini berarti model SEM dalam penelitian ini mempunyai predicted relevance yang tinggi karena nilai $\mathrm{Q}^{2}>0.00$ (layak dilakukan penelitian).

Tabel 8. Model Fit

\begin{tabular}{llll}
\hline & Saturated Model & Estimated Model \\
\hline SRMR & 0.064 & 0.064 \\
D_ULS & 0.558 & 0.558 & \\
D_G & 0.516 & 0.516 & \\
Chi-Square & 267.888 & 267.888 & \\
NFI & 0.807 & 0.807 & \\
\hline \multicolumn{2}{c}{ Berdasarkan output } & PLS diatas
\end{tabular}
didapatkan nilai normed fit index (NFI) 0.807 artinya model yang dimiliki memiliki ketepatan sebesar $81 \%$, atau nilai ketepatan atau kecocokan model tinggi karena mendekati 1.

\section{KESIMPULAN}

Hasil penelitian menyimpulkan bahwa harga berpengaruh positif namun tidak signifikan terhadap citra merek maupun keputusan pembelian. Citra merek berpengaruh positif dan signifikan terhadap keputusan pembelian dimana citra merek yang kuat tertanam dalam benak konsumen akan berdampak baik bagi konsumen untuk melakukan pembelian. Kualitas produk berpengaruh positif dan signifikan terhadap terhadap keputusan pembelian dimana kualitas produk berpengaruh positif terhadap keputusan pembelian. Citra merek merupakan moderasi potensial (Homologiser Moderator) antara harga terhadap keputusan pembelian sehingga citra merek berpotensi menjadi variabel moderasi dimana brand image mampu memediasi hubungan harga dan kualitas produk terhadap keputusan pembelian. Sementara variabel citra merek merupakan moderasi semu (quasi moderasi) antara kualitas produk terhadap keputusan pembelian sehingga citra merek bisa berposisi sebagai variabel eksogen. Model SEM dalam penelitian ini mempunyai predicted relevance yang tinggi karena nilai $\mathrm{Q}^{2}>0.00$ (layak dilakukan penelitian) sementara nilai normed fit index (NFI) 0.807 artinya model yang dimiliki memiliki ketepatan atau kecocokan tinggi karena mendekati satu.

\section{DAFTAR PUSTAKA}

Abadi, F., \& Herwin, H. (2019). Pengaruh Harga, Kualitas Produk Dan Kualitas Pelayanan Terhadap Keputusan Pembelian Beras Organik Di Jakarta. Jurnal Riset Manajemen Dan Bisnis (JRMB) Fakultas Ekonomi UNIAT, 4(1), 18. https://doi.org/10.36226/jrmb.v4i1.235

Afnina, A., \& Hastuti, Y. (2018). Pengaruh Kualitas Produk terhadap Kepuasan Pelanggan. Jurnal Samudra Ekonomi Dan Bisnis, 9(1), 21-30. https://doi.org/10.33059/jseb.v9i1.458

Anggraeni, D., Kumadji, S., \& Sunarti, S. (2016). Pengaruh Kualitas Produk Terhadap Kepuasan Dan Loyalitas Pelanggan ( Survei pada Pelanggan Nasi Rawon di Rumah Makan Sakinah Kota Pasuruan). Jurnal Administrasi Bisnis S1 Universitas Brawijaya, 37(1), 171-177.

Djatmiko, T., \& Pradana, R. (2016). Brand Image and Product Price; Its Impact for Samsung Smartphone Purchasing Decision. Procedia - Social and Behavioral Sciences, 219, 221-227. https://doi.org/10.1016/j.sbspro.2016.05.0 09

Ekonomi, F., Manajemen, P., \& Muhammadiyah, U. (n.d.). JURNAL brand image halimah. 1-19.

Fandy Tjiptono, P. . (2015). Strategi Pemasaran (Edisi ke-4). Andi Offset.

Ferrinadewi, E. (2008). Merek dan Psikologi Konsumen. Graha Ilmu.

Fristiana, D. A. (2000). Mengevaluasi Kualitas Layanan Jasa Dengan Menggunakan Model 4D. Jurnal Manajemen Dan Kewirausahaan, 2(2), 
59-67.

https://doi.org/10.9744/jmk.2.2.pp.59-67

Igir, F. G., Tampi, J. R. E., \& Taroreh, H. (2018). Pengaruh Kualitas Produk dan Harga terhadap Keputusan Pembelian Mobil Daihatsu Grand Max Pick Up. Jurnal Administrasi Bisnis, 6(2), 86-96.

Kotler, P. \& Keller, K. (2012). Marketing Management (13th ed.). Pearson Prentice Hall, Inc.

Kotler, Philip, dan G. A. (2012). Prinsipprinsip Pemasaran (13th ed.). Erlangga.

Kotler, Philip dan Amstrong, G. (2014). Principles of Marketing (12th ed.). Erlangga.

Kotler, A. (2001). Prinsip-Prinsip Pemsaran (12th ed.). Erlangga.

Kusumawardhani, R. S. (2018). Analisis Pengaaruh Kualitas Produk dan Promosi Terhadap Citra Merek dan Keputusan Pembelian Produk Sepatu Bata di Kota Semarang. Diponegoro Journal Og Management, 7(2), 1-11.

Miati, I. (2020). Pengaruh Citra Merek (Brand Image) Terhadap Keputusan Pembelian Kerudung Deenay (Studi pada Konsumen Gea Fashion Banjar). Abiwara: Jurnal Vokasi Administrasi Bisnis, 1(2), 71-83. http://ojs.stiami.ac.id/index.php/ABIWARA /article/view/795

Noerchoidah. (2013). Analisis Pengaruh Harga , Kualitas Produk Dan Iklan Terhadap Brand Image Dan Keputusan Pembelian Sepeda Motor Merek Kawasaki. Wiga, 3(1), 48-60.

Nuraini, A., Maftukhah, I., \& Artikel, I. (2015). Management Analysis Journal. 4(2), 171179.

Pekanbaru, D. I. K. (2017). No Title. 72-86.

Pradana, D., Hudayah, S., \& Rahmawati, R. (2018). Pengaruh harga kualitas produk dan citra merek BRAND IMAGE terhadap keputusan pembelian motor. Kinerja, 14(1), https://doi.org/10.29264/jkin.v14i1.2445.

Rahman. (2010). Manajemen Pemasaran dan Pemasaran Jasa. Alfabeta.

Revita Ela, M. L. D., Frimayasa, A., \& Kurniawan, A. (2018). Pengaruh Kualitas Produk Terhadap Keputusan Pembelian Smartphone Merek Samsung. Managerial - Jurnal Penelitian IImu Manajemen, 1(1), 10-10. http://journal.stiekusumanegara.ac.id/index.php/manageri al/article/view/23.

Saraswati, A., \& Rahyuda, I. (2017). Brand Image Memediasi Kualitas Produk Dan Harga Dengan Keputusan Pembelian Smartphone Apple Di Kota Denpasar. EJurnal Manajemen Universitas Udayana, 6(6), 255257.

Schiffman, Leon dan Kanuk, L. L. (2014). Perilaku Konsumen. Indeks.

Singgih Santoso. (2018). plikasi SEM Dengan AMOS 24. PT Elex Media Komputindo.

Tjiptono, F. (2012). Strategi pemasaran. Andi.

Vi, V. (2017). Penggunaan Smartphone Dalam Menunjang Aktivitas Perkuliahan Oleh Mahasiswa Fispol Unsrat Manado. VI(1), 1-15.

Wahid, M. A. (2016). Analisis pengaruh kualitas produk terhadap keputusan pembelian melalui citra merek dan nilai pelanggan. 1-19.

Widiyanto, I. (2008). Metodologi Penelitian. Badan Peerbit UNDIP.

Yoo, B., \& Donthu, N. (2001). Developing and validating a multidimensional consumerbased brand equity scale. 52.

Zhang, Z., Peng, Q., \& Gu, P. (2015). Improvement of user involvement in product design. Procedia CIRP, 36(January 2016), 267-272. https://doi.org/10.1016/j.procir.2015.01.01 9. 